\title{
Valve-sparing aortic root replacement in children: Outcomes from 100 consecutive cases
}

\author{
Charles D. Fraser III, MD, ${ }^{\mathrm{a}}$ Rui Han Liu, BS, ${ }^{\mathrm{a}}$ Xun Zhou, MD, ${ }^{\mathrm{a}}$ Nishant D. Patel, MD, ${ }^{\mathrm{a}}$ Cecillia Lui, MD, ${ }^{\mathrm{a}}$ \\ Alejandro Suarez Pierre, MD, ${ }^{\mathrm{a}}$ Marshall L. Jacobs, MD, ${ }^{\mathrm{a}}$ Harry C. Dietz, MD, ${ }^{\mathrm{b}}$ Jennifer Habashi, MD, ${ }^{\mathrm{b}}$ \\ Narutoshi Hibino, MD, ${ }^{a}$ Duke E. Cameron, $\mathrm{MD},{ }^{\mathrm{c}}$ and Luca A. Vricella, $\mathrm{MD}^{\mathrm{a}}$
}

\section{ABSTRACT}

Objective: Valve-sparing root replacement is an attractive alternative to composite mechanical or biologic prostheses for aortic root aneurysms in children. Data on outcomes in pediatric patients are limited. We present our institutional experience with 100 consecutive pediatric valve-sparing aortic root procedures.

Methods: All children who underwent valve-sparing root replacement at our institution from May 1997 to August 2017 were identified, and echocardiographic and clinical data were reviewed. The primary end point was mortality, and secondary end points included complications, further interventions, and subsequent valvular dysfunction.

Results: Median age at operation was 13.6 years (interquartile range, 9.42-15.9); 51 patients $(51 \%)$ had Marfan syndrome, and 39 patients $(39 \%)$ had Loeys-Dietz syndrome. Mean preoperative maximum sinus diameter was $4.4 \pm 0.71 \mathrm{~cm}$ ( $z$ score 7.3 [5.7-9.3]). Most patients $(n=80,80 \%)$ underwent reimplantation procedures with a Valsalva graft. Four patients (4\%) underwent David I reimplantation with a straight-tube graft, 13 patients (13\%) underwent a Yacoub remodeling procedure, and 3 patients $(3 \%)$ underwent a Florida sleeve procedure. Perioperative valve-sparing root replacement mortality was $2 \%(n=2)$. Six patients required late reintervention for development of pseudoaneurysms. Eight patients underwent additional aortic surgery. Average time to reoperation was $7.23 \pm 4.56$ years. Of the 84 patients undergoing a reimplantation procedure, 5 $(5.9 \%)$ underwent late valve replacement versus $5(33.3 \%)$ of the 15 patients who received a remodeling procedure $(P=.001)$.

Conclusions: Valve-sparing root replacement is a safe and effective option for children with aortic root aneurysms in children. The reimplantation procedure is preferred. Late aortic insufficiency and pseudoaneurysm formation remain late concerns. (J Thorac Cardiovasc Surg 2019;157:1100-9)

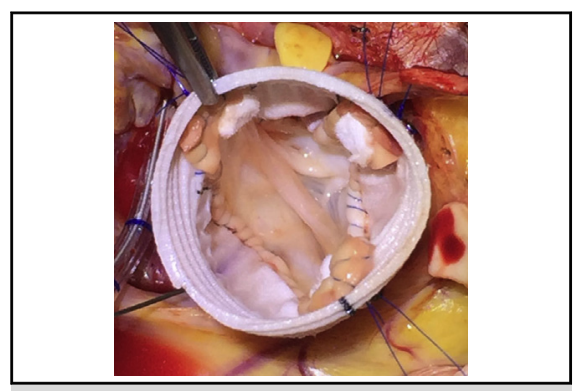

Reimplantation valve-sparing aortic root replacement in a child with connective tissue disease and a bicuspid aortic valve.

Central Message

VSRR is an effective option for children with aortic root aneurysms and avoids complications of prostheses. AI and pseudoaneurysms remain late concerns.

\section{Perspective}

In the largest series of valve-sparing root procedures performed in children, valve preservation provides a safe and effective means to avoid the potential complications of valve prostheses. Comprehensive surgical guidelines for children with aortic root dilatation remain ill defined. These data provide evidence to support management strategies for children presenting with proximal aortic aneurysms.

See Commentaries on pages 1110 and 1112.
Aortic root replacement is often performed for aneurysms of the proximal aorta and aortic sinuses, as well as for dissection, endocarditis, and many other diseases involving

From the a Division of Cardiac Surgery and ${ }^{b}$ Department of Pediatrics, The Johns Hopkins Hospital, Baltimore, Md; and ${ }^{\mathrm{c}}$ Division of Cardiac Surgery, The Massachusetts General Hospital, Boston, Mass.

Institutional Review Board approval: NA_00001068.

Read at the 98th Annual Meeting of The American Association for Thoracic Surgery, San Diego, California, April 28-May 1, 2018.

Received for publication April 29, 2018; revisions received Sept 13, 2018; accepted for publication Sept 21, 2018.

Address for reprints: Charles D. Fraser III, MD, 1800 Orleans, Zayed Tower 7107, Baltimore, MD 21287 (E-mail: Cfrase11@jhmi.edu).

$0022-5223 / \$ 36.00$

Copyright (c) 2018 by The American Association for Thoracic Surgery

https://doi.org/10.1016/j.jtcvs.2018.09.148 the base of the aorta and aortic valve. The traditional surgical approach for these pathologies has been to replace the aortic root with concomitant aortic valve replacement (AVR) using a valve-and-graft composite, the so-called Bentall procedure. Results from the Bentall aortic root

Scanning this QR code will take you to the article title page to access supplementary information. To view the AATS Annual Meeting Webcast, see the URL next to the webcast thumbnail. 


\section{Abbreviations and Acronyms \\ $\mathrm{AI}=$ aortic insufficiency \\ AVR $=$ aortic valve replacement \\ IQR = interquartile range \\ LDS = Loeys-Dietz syndrome \\ $\mathrm{VSRR}=$ valve-sparing root replacement}

replacement have yielded low operative mortality and low morbidity at follow-up. However, AVR with prosthetic valves typically mandates lifelong anticoagulation for mechanical valves or potential need for reoperation related to degeneration of bioprosthetic valves. Because of these and other associated risks of valve prostheses, valve preservation in aortic root replacement has been developed over the past few decades to improve the quality of life for patients requiring these procedures. Valve-sparing root replacement (VSRR) has evolved through the pioneering work of surgeons such as David and colleagues, ${ }^{1}$ David and Feindel, ${ }^{2}$ and Sarsam and Yacoub. ${ }^{3}$

Aortic root aneurysms are rare in children; they are usually associated with connective tissue diseases or conotruncal congenital heart anomalies, or may present after operative management of other congenital heart pathologies. Aortic root replacement may be indicated in these children to prevent risk of aneurysm rupture, aortic dissection, or progressive aortic valve incompetence. However, absolute indications for intervention in children remain elusive given the absence of predictors of dissection or rupture in pediatric patients and the diverse population of children presenting with aneurysms. ${ }^{4}$ Nonetheless, aortic root replacement is often undertaken to mitigate the risk of aortic catastrophe.

VSRR is an appealing approach in children with aortic root aneurysms because it allows for avoidance of the problems associated with long-term anticoagulation, carries a low risk of thromboembolism or endocarditis, and has shown promising intermediate-term outcomes. ${ }^{5}$ In this article, we review our 20-year experience with 100 consecutive VSRR procedures in children with proximal aortic aneurysms.

\section{MATERIALS AND METHODS \\ Patient Selection}

After Institutional Review Board approval, data were collected retrospectively for all children (age $<18$ years) who underwent VSRR between May 1997 and September 2017 at The Johns Hopkins Hospital. Data were obtained from medical and electronic patient records. A waiver for individual consent was granted by the Institutional Review Board.

All patients receiving VSRR had transthoracic echocardiograms to assess preoperative and postoperative aortic valve function and proximal aortic dimensions. Intraoperative transesophageal echocardiograms were routinely obtained. Echocardiographic data included aortic root diameters with respective $Z$ scores and degree of aortic insufficiency (AI) (0-4+). Clinical follow-up data, including need for reoperation on the aortic root, bleeding, thromboembolic events, and need for subsequent cardiovascular intervention, were obtained by telephone interview with the patient, family members, or primary care physicians. Follow-up surveillance strategies vary by underlying disease processes.

\section{Statistical Analysis}

Statistical analyses were conducted using STATA version 14.0 (StataCorp, LP, College Station, Tex) software package. Descriptive statistics for continuous variables were listed as mean \pm standard deviation for parametric data or median (interquartile range [IQR]) for nonparametric data and compared using Student $t$ test or Wilcoxon rank-sum test, respectively. Categoric data were listed as $\mathrm{n}(\%)$ and compared using chi-square testing. Survival and freedom from reoperation of the aortic root were estimated using the Kaplan-Meier method. Also, freedom from 3 to $4+\mathrm{AI}$ and freedom from AVR were calculated.

\section{Surgical Technique and Postoperative Management}

Our current operative technique for the reimplantation VSRR has been described in detail. ${ }^{6,7}$ All operations are performed via a median sternotomy and cardiopulmonary bypass using aortic bicaval venous cannulation. After incising the aorta above the sinotubular ridge, the diameter of the sinotubular junction that provides optimal leaflet apposition is determined using commercial valve sizers and select a Valsalva graft that is 2 to $3 \mathrm{~mm}$ larger to accommodate the prosthesis. The base of the aorta is dissected externally down to a subannular level. This is followed by excision of sinus tissue, leaving an approximately 4 to 5-mm sinus remnant attached to the annulus. The coronary arteries are mobilized. Three 3-0 horizontal mattress sutures are passed under the annulus at the nadir of each aortic leaflet from inside outward. Our procedure differs from the original David I reimplantation technique in that only 3 subannular sutures are placed. The subannular sutures anchor the graft and ensure that the entire aortic valve complex is within the sinus segment of the Valsalva graft. The 3 subannular sutures are passed inside-out through the bottom of the Valsalva graft 120 degrees apart from each other. The stay sutures are drawn up within the graft, which is lowered around the valve complex, and the 3 subannular sutures are tied. The commissures are fixed to the sinotubular junction of the Valsalva graft using three 4-0 polypropylene pledgeted mattress sutures. In most patients, the commissural height is level with the sinotubular ridge of the graft. In patients with very large roots and tall commissures, fixation can be just above the ridge.

The valve is now properly positioned within the graft by the " 3 below" and the " 3 above" fixation sutures. Starting at the bottom of each sinus and sewing upward to the commissure tops, continuous 4-0 polypropylene sutures are used to fix the sinus remnant and annulus within the graft. This is the hemostatic suture line. Holes are cut in the graft opposite the coronary artery buttons. We encircle the coronary buttons with polytetrafluoroethylene felt pledgets. The left and right coronary anastomoses are completed with 4-0 polypropylene. Finally the distal graft is anastomosed to the aorta using a continuous 4-0 polypropylene suture and an external felt strip. Air is evacuated from the heart, the aortic crossclamp is removed, and the heart is resuscitated. ${ }^{6,8,9}$

The Florida Sleeve technique for aortic root remodeling with preservation of the aortic valve and sinuses has been described in great detail previously. ${ }^{10}$ This technique was used in a small number of patients early in our experience with VSRR in children. In summary, this technique uses an external Dacron sleeve graft to encase the aortic root. Horizontal mattress sutures are placed below the level of the aortic annulus and driven outside the aorta. The locations of the coronary arteries are marked on the graft, and slits are created in the graft at the marks to accommodate the coronary arteries followed by creation of "coronary key holes." The subannular sutures are then passed through the base of the graft, aligning the key holes to encase the coronary arteries. The distal portion of the graft is anastomosed to the ascending aorta or to an ascending aortic graft to complete root remodeling. ${ }^{10}$

Routine long-term management after VSRR includes aspirin for anticoagulation, typically begun on the first postoperative day and continued for 1 month, and beta-blockers to minimize hemodynamic stress. Duration of beta-blockade is determined by underlying disease processes, because 
TABLE 1. Preoperative patient characteristics

\begin{tabular}{|c|c|}
\hline Demographic & Total $(\%)$ \\
\hline Total, $\mathrm{n}$ & 100 \\
\hline Median age at operation, y (IQR) & $13.6(9.42-15.9)$ \\
\hline Male & $67(67 \%)$ \\
\hline \multicolumn{2}{|l|}{ Ethnicity } \\
\hline White & $80(80 \%)$ \\
\hline African American & $7(7 \%)$ \\
\hline Hispanic & $2(2 \%)$ \\
\hline Asian & $1(1 \%)$ \\
\hline Other & $10(10 \%)$ \\
\hline Marfan syndrome & $51(51 \%)$ \\
\hline LDS & $39(39 \%)$ \\
\hline Previous cardiac surgery & $8(8 \%)$ \\
\hline Preoperative maximum sinus diameter $(\mathrm{cm})$ & $4.379 \pm 0.713$ \\
\hline Preoperative maximum sinus $Z$ score, median (IQR) & $7.3(5.7-9.3)$ \\
\hline Preoperative STJ diameter $(\mathrm{cm})$ & $3.06 \pm 0.874$ \\
\hline Preoperative STJ $Z$ score, median (IQR) & $3.9(2.5-6.6)$ \\
\hline Preoperative annular diameter $(\mathrm{cm})$ & $2.31 \pm 0.374$ \\
\hline Preoperative annular $Z$ score, median (IQR) & $2.9(1.7-4.9)$ \\
\hline Preoperative $>2$ (mild) AI & $7(7 \%)$ \\
\hline Bicuspid aortic valve & $12(12 \%)$ \\
\hline Preoperative $>2$ (mild) mitral insufficiency & $1(1 \%)$ \\
\hline Preoperative $>2$ (mild) mitral stenosis & $1(1 \%)$ \\
\hline \multicolumn{2}{|l|}{ Preoperative NYHA class } \\
\hline Class I & $96(96 \%)$ \\
\hline Class II & $4(4 \%)$ \\
\hline
\end{tabular}

$I Q R$, Interquartile range; $L D S$, Loeys-Dietz syndrome; $S T J$, sinotubular junction; $A I$, aortic insufficiency; NYHA, New York Heart Association.

children with connective tissue diseases warrant indefinite beta-blockade. Postoperative echocardiography is typically obtained before discharge from the hospital, and surveillance echocardiography or computed tomographic angiography occurs annually or more frequently dependent on the presence, type, and severity of connective tissue disease.

\section{RESULTS}

\section{Preoperative Clinical Characteristics}

In total, 100 children, median age 13.6 years (IQR, 9.4215.9), underwent VSRR during the 20-year study period. Baseline demographic and clinical data are summarized in Table 1. A total of 51 patients (51\%) had Marfan syndrome, and 39 patients $(39 \%)$ had Loeys-Dietz syndrome (LDS). Mean preoperative maximum sinus diameter was $4.4 \pm 0.71 \mathrm{~cm}(Z$ score $7.3 ;$ IQR, 5.7-9.3). Mean preoperative annular diameter was $2.31 \pm 0.374 \mathrm{~cm}(Z$ score 2.9 ; IQR, 1.74.9). Mean preoperative sinotubular junction diameter was $3.06 \pm 0.874$ ( $Z$ score 3.9; IQR, 2.5-6.6). Seven patients $(7 \%)$ had greater than mild $(>2)$ AI preoperatively. Twelve patients $(12 \%)$ had bicuspid aortic valves. Ninety-six patients (96\%) had New York Heart Association class I preoperatively, and 4 patients (4\%) had New York Heart Association class II.

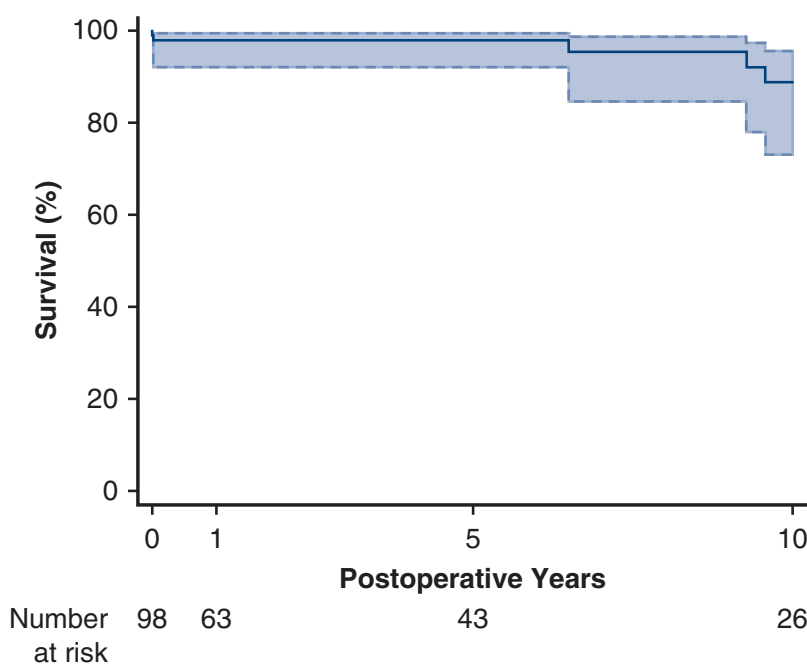

FIGURE 1. Kaplan-Meier all-cause survival curve in children after valve-sparing aortic root replacement. Dashed line indicates $95 \%$ confidence intervals.

\section{Operative Data}

Most patients $(\mathrm{n}=80,80 \%)$ underwent reimplantation procedures with a Valsalva graft. Four patients $(4 \%)$ underwent reimplantation with a straight-tube graft, 13 patients $(13 \%)$ underwent a Yacoub remodeling procedure, and 3 patients $(3 \%)$ underwent a Florida sleeve procedure. Mean cardiopulmonary bypass and crossclamp times were $151.2 \pm 27.9$ and $106.7 \pm 21.4$ minutes, respectively. The most common prosthesis size used was a $24-\mathrm{mm}$ graft, with graft sizes ranging from 20 to $32 \mathrm{~mm}$.

We routinely inspect for and close the patent foramen ovale when present. In total, 52 patients $(52 \%)$ had a patent foramen ovale closure at the time of VSRR. Five patients $(5 \%)$ had a concomitant patent ductus arteriosus ligation. One patient underwent concomitant hemiarch replacement. Nine patients $(9 \%)$ had aortic valve repairs performed at the time of VSRR.

\section{Survival}

Median follow-up time was 4.7 years (IQR, 0-10 years). Perioperative VSRR mortality was $2 \%(n=2)$. Both patients had severe infantile Marfan syndrome and underwent VSRR at early ages. One was a 4-year-old girl with Marfan syndrome who underwent VSRR and mitral valve repair and experienced massive postoperative bleeding and ventricular dysfunction, requiring institution of extracorporeal membrane oxygenation. The second was a 2-year-old boy with an aortic root aneurysm and severe arterial tortuosity throughout the arterial tree. He underwent a VSRR with ASD closure, and his postoperative course was complicated by vasoplegia, low cardiac output syndrome, and eventually ventricular fibrillation and cardiac arrest. Seven patients $(7 \%)$ experienced late mortality. Four of these were related 
TABLE 2. Preoperative versus follow-up echocardiography data

\begin{tabular}{lcccc}
\hline & Preoperative echocardiography & Follow-up echocardiography & $\boldsymbol{P}$ value* & Effect size, r \\
\hline Annulus $(\mathrm{cm})$ & $2.31 \pm 0.374$ & $2.16 \pm 0.38$ & .08 & 0.2 \\
Annulus $Z$ score & $3.07 \pm 2.1$ & $1.16 \pm 0.31$ & $<.001$ & 1.91 \\
Maximum sinus $(\mathrm{cm})$ & $4.44 \pm 0.76$ & $3.09 \pm 0.55$ & $<.001$ & 1.29 \\
Maximum sinus $Z$ score & $7.55 \pm 2.52$ & $1.35 \pm 1.73$ & 6.2 \\
Sinotubular junction diameter $(\mathrm{cm})$ & $3.03 \pm 0.84$ & $2.58 \pm 0.47$ & $<.001$ & $\mathbf{. 0 0 2}$ \\
Sinotubular junction $Z$ score & $4.34 \pm 3.31$ & $1.36 \pm 1.78$ & $<.46$ \\
\hline
\end{tabular}

*Student $t$ test, preoperative versus most recent follow-up echocardiography data. Significant differences in bold, defined as $P<.05$

to complications of type B aortic dissections in children with connective tissue disease. Overall Kaplan-Meier 1-, 5 -, and 10-year survivals were $97 \%, 97 \%$, and $88 \%$, respectively (Figure 1).

\section{Late Outcomes}

Proximal aortic measurements from the most recent follow-up echocardiography data were compared with preoperative echocardiography measurements (Table 2), showing resolution of preoperative annular, maximum sinus, and sinotubular junction dilatation. In total, 15 patients underwent reintervention related to their index VSRR procedure. Freedom for reintervention is depicted in Figure 2. When comparing remodeling and reimplantation techniques, the reimplantation technique resulted in a superior freedom from reintervention at 5 years $(94.5 \%$ vs $75.0 \%$, $P=.043)$ and 10 years $(78.6 \%$ vs $54.6 \%, P=.038)$ (Figure 2, B). All 3 patients who had a Florida sleeve required subsequent reimplantation VSRR. Five patients required late reintervention for development of pseudoaneurysms. One patient developed pseudoaneurysms of the coronary button anastomoses requiring revision of the coronary anastomoses. ${ }^{11,12}$ The average time to reoperation for pseudoaneurysm repair was $6.6 \pm 4.0$ years. Eight patients underwent additional aortic surgery of the ascending aorta

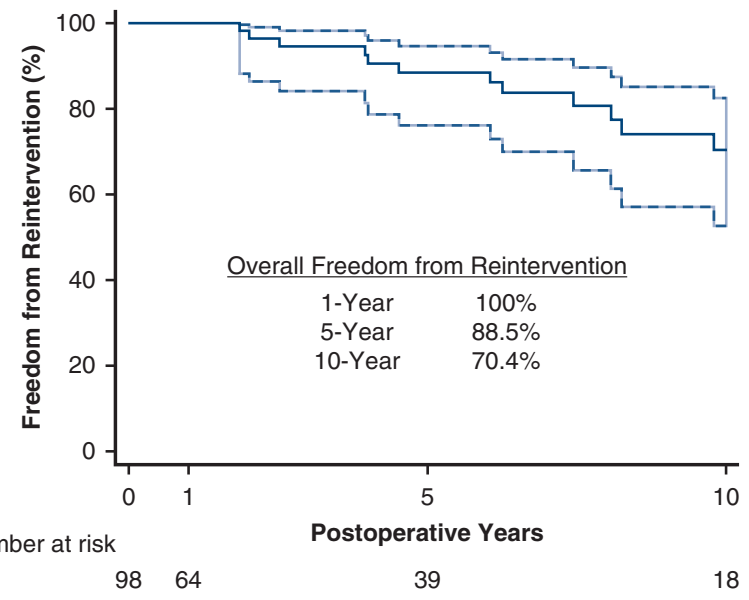

A

FIGURE 2. Kaplan-Meier freedom from reintervention for all children undergoing VSRR (A) and by VSRR technique (reimplantation vs remodeling procedures) (B). Dashed lines represent corresponding $95 \%$ confidence intervals. and aortic arch. Of these, 6 children had severe subtypes of LDS, and 2 children had Marfan syndrome. The average time to reoperation for subsequent aortic surgery was $7.23 \pm 4.56$ years. Of these reoperations for additional aortic replacements, only 1 patient had a late postoperative mortality 4.8 years after reoperation secondary to complications related to a type B aortic dissection.

In total, 9 patients developed significant AI, defined as moderate or greater, and required subsequent AVR. Average time to AVR after VSRR was $5.98 \pm 4.1$ years. Progression of annular diameter and maximum sinus diameter in those requiring AVR is depicted in Figure 3, $A$ and $B$, respectively. The cause of the progression of AI in these patients was dilatation of the aortic annulus (Figure 3, A). KaplanMeier freedom from AVR is depicted in Figure 4. Of the 84 patients undergoing a reimplantation procedure, 4 (4.8\%) underwent late AVR versus $5(31.3 \%)$ of the $16 \mathrm{pa}-$ tients who underwent a remodeling procedure $(P=.001)$. Four patients requiring AVR had late mortality after valve replacement, with an average time from AVR to mortality of $4.7 \pm 2.8$ years. Of the 12 patients with bicuspid aortic valves, none have required subsequent reoperation for progressive aortic valve insufficiency. Finally, during the study period, 7 pediatric patients underwent Bentall procedures

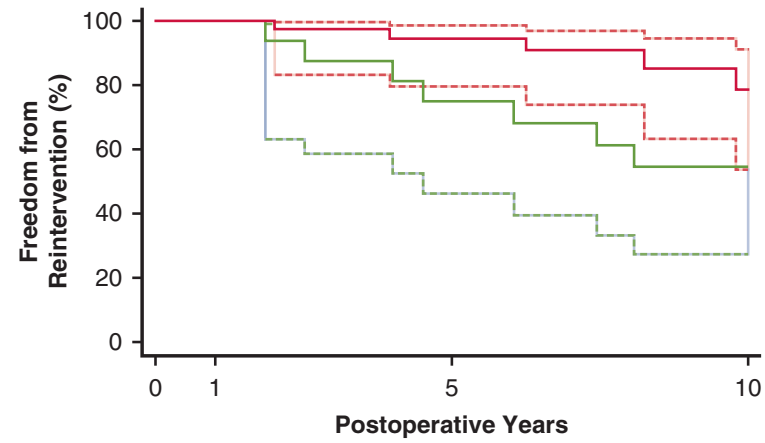

Number at risk

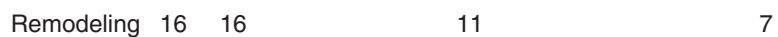

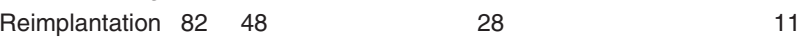

B $\quad$ Remodeling Reimplantation 

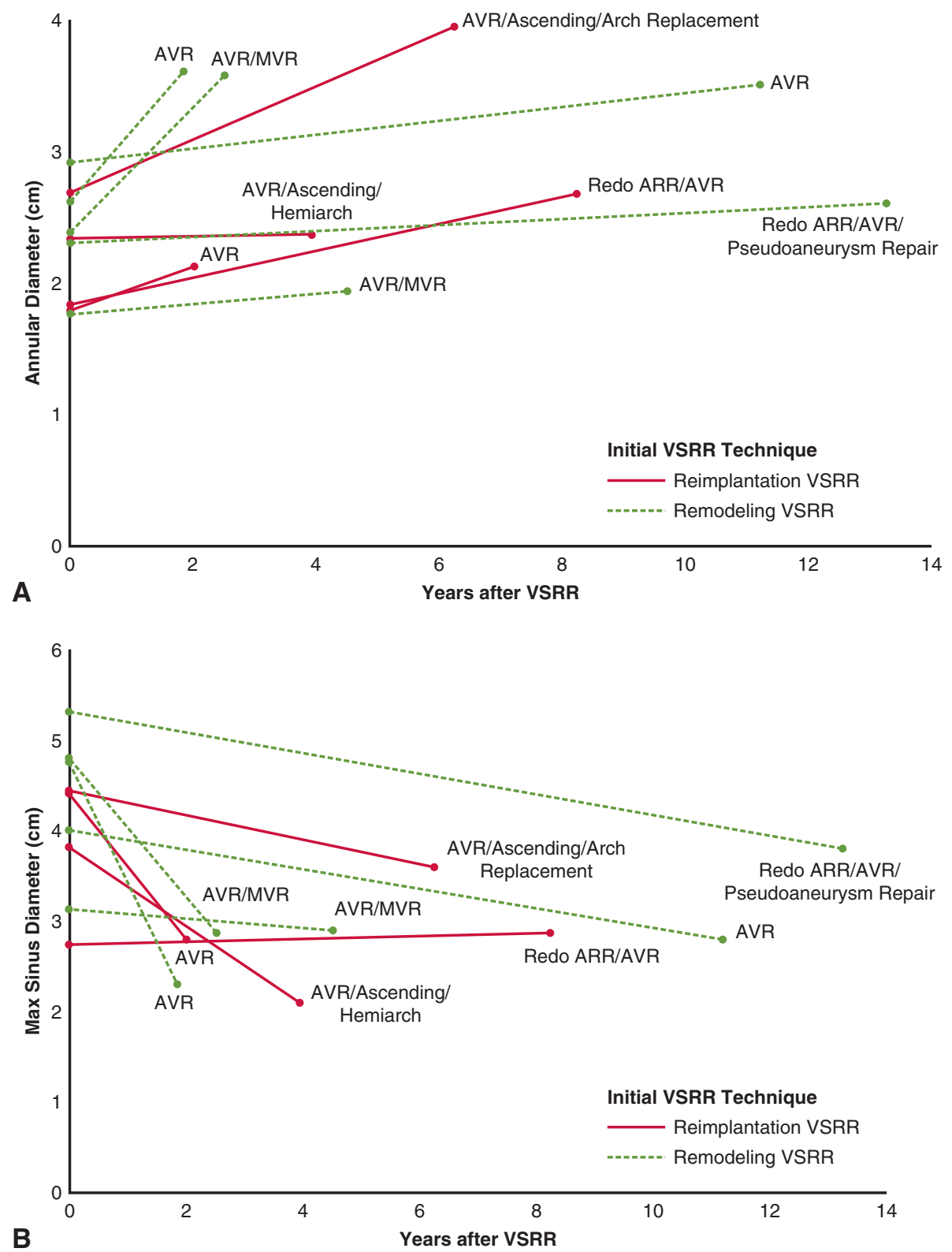

FIGURE 3. Progression of annular diameter (A) and maximum sinus diameter (B) in those children requiring subsequent AVR after VSRR. The red lines represent those patients who underwent a reimplantation VSRR initially, and the green dashed line represents those patients who underwent a remodeling VSRR. AVR, Aortic valve replacement; $M V R$, mitral valve replacement; $A R R$, aortic root replacement; VSRR, valve-sparing root replacement.

with mechanical aortic valve prostheses; these were excluded for the purposes of this study.

\section{DISCUSSION}

The management of proximal aortic aneurysms in patients with connective tissue diseases has been well studied in the adult population. Results after the Bentall operation have been excellent and reproducible at longterm follow in adults with aortic root aneurysms. ${ }^{9,13-15}$ However, given the risks associated with mechanical prostheses and the lifestyle limitations associated with anticoagulation, valve preservation has evolved as an attractive alternative to the Bentall operation. In children with severe connective tissue diseases, aortic catastrophe remains a rare but important cause of death; therefore, strong consideration should be given for surgical intervention when these patients present with aortic root aneurysms.

Our experience with valve-sparing aortic root procedures in children has recently reached 100 consecutive cases (Video 1). Early in our series, we favored the remodeling technique (Yacoub/David II) for valve preservation because 


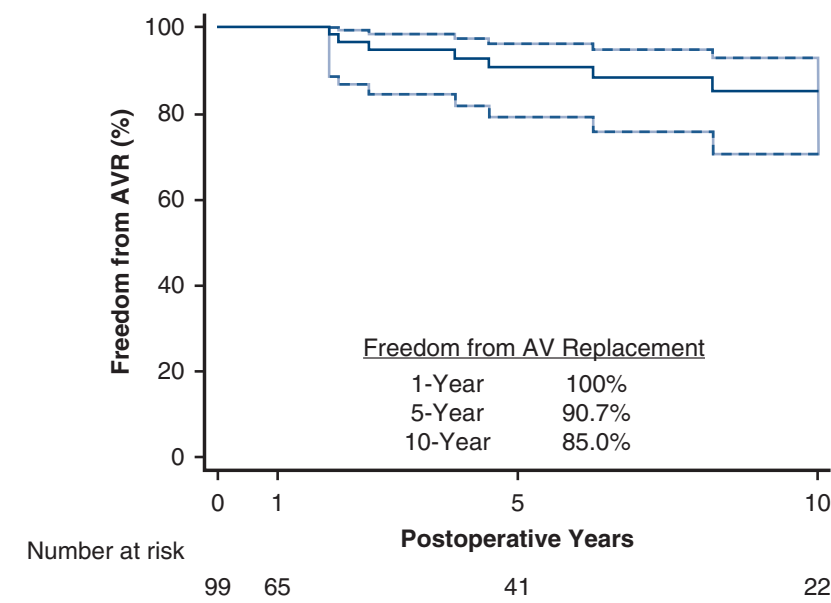

A

FIGURE 4. Kaplan-Meier freedom from AVR for all children undergoing VSRR (A) and by VSRR technique (reimplantation vs remodeling procedures) (B). Dashed lines represent corresponding 95\% confidence intervals. AV, Aortic valve; $A V R$, aortic valve replacement.

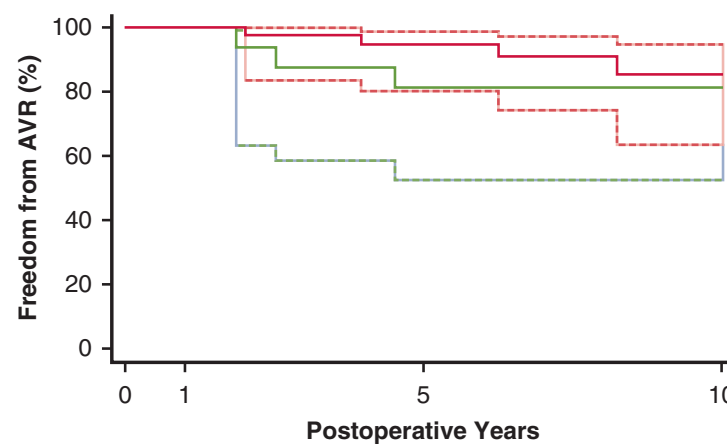

Number at risk

Remodeling $16 \quad 16$

Reimplantation $83 \quad 49 \quad 29$

10

12

B - Remodeling — Reimplantation of the theoretical advantage of preserving sinuses because this was thought to minimize leaflet stress by allowing a more physiologic valve leaflet excursion. ${ }^{16}$ However, we observed a trend toward late annular dilatation in those children undergoing remodeling VSRR, and, in some patients, late AI developed, requiring subsequent AVR. ${ }^{17}$ Since 2002, we have largely abandoned remodeling techniques and prefer a modified David V reimplantation technique using the Valsalva graft (Gelweave Valsalva graft; Vaskutek, Renfrewshire, Scotland, UK), which has the advantage of preservation of sinus-like geometry, improved annular stabilization, and better hemostasis. ${ }^{18}$

Other important intraoperative considerations when performing VSRR include the management of bicuspid aortic valves and prosthesis size matching. Although the presence of a bicuspid aortic valve is not a contraindication to valve preservation, careful attention must be made during VSRR to preserve valve function. The primary objective in VSRR in bicuspid valves should be to maintain the geometry of the commissural posts, as is the case with tricuspid valves. In children with bicuspid valves undergoing VSRR, maintaining appropriate geometry when suspending the commissures is critical to ensuring postoperative valve competence. In terms of aortic graft prosthesis sizing, we only use a second prosthesis if simultaneous aortic arch or hemiarch replacement is performed. In the majority of patients, the aorta just proximal to the take-off of the brachiocephalic artery is normal in diameter and usually large enough for a small adult. In these cases, the distal aspect of the prosthesis is tailored to the native distal ascending aorta by 3 equidistant placating sutures. We have never had to intervene because of supravalvular AS caused by prosthetic-aortic mismatch.

Long-term data regarding the durability of valve preservation in aortic root replacement are lacking in children.
We have previously reported our short- and intermediate-term experience with VSRR in pediatric patients. $^{4,8,19}$ In those studies, early outcomes were favorable, showing superiority of the reimplantation technique in children in terms of survival, postoperative annular dilatation, and freedom from AVR. In this review of the first 100 cases of VSRR in children at our institution, outcomes remain encouraging. Perioperative and all-cause long-term mortality were exceedingly low. In the patients who had late mortality, the majority were due to fatal intracerebral or distal aortic catastrophes and none were the result of late complications of their aortic root procedures. In addition, some required subsequent reoperation for ascending aortic and hemiarch replacements. With this in mind, we are reconsidering the management of the distal ascending aorta as well as the arch in those children with severe connective tissue diseases. More aggressive surgical replacement of the distal ascending aorta may be warranted because some of our patients

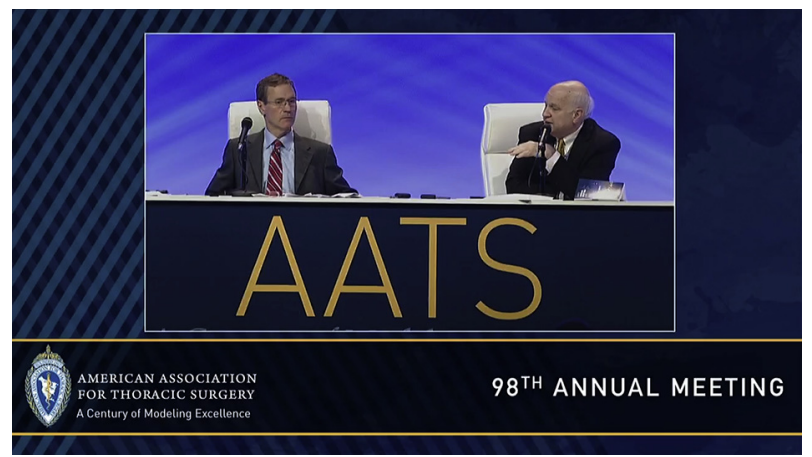

VIDEO 1. Our experience with pediatric valve-sparing aortic root replacement was presented and discussed at the 98th annual meeting of The American Association for Thoracic Surgery. Video available at: https://www.jtcvs.org/article/S0022-5223(18)33223-9/fulltext. 
TABLE 3. Current guidelines for aortic root replacement at our institution

\begin{tabular}{cc}
\hline \multicolumn{1}{c}{ Diagnosis } & Indications for VSRR in children \\
\hline Marfan syndrome & Maximum diameter $>5.0 \mathrm{~cm}$ or \\
& increase of $>0.5 \mathrm{~cm} / \mathrm{y}$ \\
& Diameter of $4.5-5.0 \mathrm{~cm}$ if: \\
& Family history of or rupture \\
& Aortic valve regurgitation \\
& Need for mitral valve repair and aortic \\
& root $4.0-5.0 \mathrm{~cm}$
\end{tabular}

VSRR, Valve-sparing root replacement; $L D S$, Loeys-Dietz syndrome.

have required subsequent ascending and hemiarch replacements. Our experience also highlights the durability of the reimplantation technique even in patients with connective tissue disease, with an overall freedom from AVR of $97 \%$ at 5 years and $85 \%$ at 10 years. The need for reoperation secondary to aortic valve insufficiency was rare, and our experience corroborates other studies in that the reimplantation technique is superior and results in a significantly greater freedom from AVR.

Institutional experience and patient selection are important factors and relate to outcomes after VSRR, particularly in children. At our institution, guidelines for surgical intervention on aortic root aneurysms in children are driven by the presence of connective tissue diseases and the type or severity of disease. Our current guidelines are summarized in Table 3. In children with Marfan syndrome, we proceed with surgical intervention for aortic root aneurysms once the annular diameter has reached $5 \mathrm{~cm}$ or if the aneurysm is enlarging more than $0.5 \mathrm{~cm}$ per year. However, in some instances, we will advocate earlier intervention if a child with Marfan syndrome presents with a family history of aortic catastrophe, has progressive AI, or has mitral valve pathology necessitating intervention. The management of aortic root aneurysms in children with LDS is dictated on the basis of disease subtype. There are currently 4 subtypes of LDS with varying phenotypes and disease severity. ${ }^{20}$ Given the heterogeneity of the vascular phenotypes, the guidelines for intervention in patients with LDS remains elusive. This is further compounded by the difficulty in assessing progressive enlargement in the growing child. A threshold of $4 \mathrm{~cm}$ has been used for patients with worse genotype (LDS types I and II), very pronounced craniofacial dysmorphic features, or high vertebral tortuosity index. The prominence of these 2 associated clinical anomalies has been associated with a more aggressive vascular phenotype, prompting intervention at diameters less than $4.0 \mathrm{~cm} \cdot{ }^{20-22}$ As such, we are most aggressive with early surgical intervention in these types of LDS (Table 3), advocating for surgery at an aortic root size of $3.5 \mathrm{~cm}, Z$ score greater than 3.0, or aortic root expanding greater than $0.5 \mathrm{~cm} /$ year. For patients lacking these features and disclosing a less concerning genotype, a threshold of $4.5 \mathrm{~cm}$ has been used in our practice. It is our hope that as the genetic and clinical features of particular patient population are further investigated, a more evidence-based decision-making algorithm might be developed. For the time being, our group continues to advocate aggressive prophylactic surgery for this high-risk group of patients.

Not all children presenting with connective tissue diseases and aortic root aneurysms are offered VSRR. Our relative contraindications for VSRR in children include marked leaflet fenestration and asymmetry, acute aortic dissection in unstable patients, a giant root with marked leaflet irregularities, or bicuspid aortic valves with extensive calcification, severe prolapse, and marked fenestrations. In the case of excessive fenestrations, we will at times still proceed with VSRR in those children with fenestrations but a competent aortic valve. ${ }^{23,24}$ Other reasons that a child may not be deemed a candidate for VSRR include "ventricularization" of the sinuses, most often the right, with fusion between myocardium and aortic wall precluding deep dissection of the sinuses, and, in some cases, the need for mitral valve replacement.

We recommend that after VSRR, all children undergo echocardiography, computed tomography, or magnetic resonance imaging 6 months postoperatively and annually thereafter. For children with LDS and severe Marfan syndrome, we recommend echocardiography every 3 to 6 months for 1 year after surgery and every 6 months thereafter, as well as full body computed tomography or magnetic resonance imaging scanning yearly.

\section{CONCLUSIONS}

VSRR is a safe and effective option for children with aortic root aneurysms and avoids the potential complications of valve prostheses. The reimplantation procedure with the Valsalva graft produces better results when compared with other techniques in our experience by stabilizing the aortic root, improving hemostasis, and preserving sinuses; therefore, we have abandoned remodeling procedures in children. However, AI and pseudoaneurysm 
formation remain a late concern, and as such, long-term follow-up in children requiring VSRR is warranted.

\section{Webcast}

You can watch a Webcast of this AATS meeting presentation by going to: https://aats.blob.core.windows.net/ media/18Apr30/20ABC\%201.Plenary \%20Sessions/S57\% 20-\%20Part\%201/S57_3.mp4.

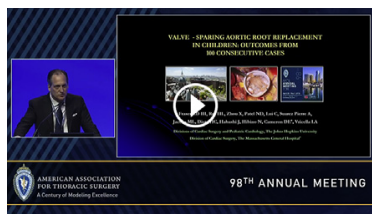

\section{Conflict of Interest Statement}

Authors have nothing to disclose with regard to commercial support.

\section{References}

1. David TE, Feindel CM, David CM, Manlhiot C. A quarter of a century of experience with aortic valve-sparing operations. J Thorac Cardiovasc Surg. 2014;148: 872-9.

2. David TE, Feindel CM. An aortic valve-sparing operation for patients with aortic incompetence and aneurysm of the ascending aorta. J Thorac Cardiovasc Surg. 1992; 103:617-22.

3. Sarsam MA, Yacoub M. Remodeling of the aortic valve annulus. J Thorac Cardiovasc Surg. 1993;105:435-8.

4. Patel ND, Alejo D, Crawford T, Hibino N, Dietz HC, Cameron DE, Vricella LA. Aortic root replacement for children with Loeys-Dietz syndrome. Ann Thorac Surg. 2017;103:1513-8.

5. Patel ND, Arnaoutakis GJ, George TJ, Allen JG, Alejo DE, Dietz HC, et al. Valve-sparing aortic root replacement in children: intermediate-term results. Interact Cardiovasc Thorac Surg. 2011;12:415-9.

6. Cameron D, Vricella L. Valve-sparing aortic root replacement with the Valsalva graft. Oper Tech Thorac Cardiovasc Surg. 2005;10:259-71.

7. Vricella LA, Cameron DE. Valve-sparing aortic root replacement in pediatric patients: lessons learned over two decades. Semin Thorac Cardiovasc Surg Pediatr Card Surg Annu. 2017;20:56-62.

8. Patel ND, Arnaoutakis GJ, George TJ, Allen JG, Alejo DE, Dietz HC, et al. Valve-sparing aortic root replacement in Loeys-Dietz syndrome. Ann Thorac Surg. 2011;92:556-61.

9. Cameron DE, Alejo DE, Patel ND, Nwakanma LU, Weiss ES, Vricella LA, et al. Aortic root replacement in 372 Marfan patients: evolution of operative repair over 30 years. Ann Thorac Surg. 2009;87:1344-50.

10. Hess PJ, Klodell CT, Beaver TM, Martin TD. The Florida sleeve: a new technique for aortic root remodeling with preservation of the aortic valve and sinuses. Ann Thorac Surg. 2005;80:748-50.

11. Fraser CD, Zhou X, Liu RH, Lui C, Cameron DE, Jacobs ML, et al. Coronary button pseudoaneurysms after aortic root replacement in a child with LoeysDeitz syndrome. Ann Thorac Surg. 2018;105:e63-5.

12. Liu RH, Fraser CD, Zhou X, Cameron DE, Vricella LA, Hibino N. Pseudoaneurysm formation after valve sparing root replacement in children with Loeys-Dietz syndrome. J Card Surg. 2018;33:339-43.

13. Williams JA, Loeys BL, Nwakanma LU, Dietz HC, Spevak PJ, Patel ND, et al. Early surgical experience with loeys-dietz: a new syndrome of aggressive thoracic aortic aneurysm disease. Ann Thorac Surg. 2007;83:S757-63.

14. Gott VL, Cameron DE, Alejo DE, Greene PS, Shake JG, Caparrelli DJ, Dietz HC Aortic root replacement in 271 Marfan patients: a 24-year experience. Ann Thorac Surg. 2002;73:438-43.

15. Gott VL, Greene PS, Alejo DE, Cameron DE, Naftel DC, Miller DC, et al. Replacement of the aortic root in patients with Marfan's syndrome. $N$ Engl J Med. 1999;340:1307-13.
16. Grande-Allen KJ, Cochran RP, Reinhall PG, Kunzelman KS. Re-creation of sinuses is important for sparing the aortic valve: a finite element study. J Thorac Cardiovasc Surg. 2000;119:753-63.

17. Results of aortic valve-sparing operations: experience with remodeling and reimplantation procedures in 65 patients. Ann Thorac Surg. 2004;78:767-72.

18. Valve-sparing aortic root replacement: early experience with the De Paulis Valsalva graft in 51 patients. Ann Thorac Surg. 2006;82:548-53.

19. Vricella LA, Williams JA, Ravekes WJ, Holmes KW, Dietz HC, Gott VL, et al. Early experience with valve-sparing aortic root replacement in children. Ann Thorac Surg. 2005;80:1622-7.

20. MacCarrick G, Black JH, Bowdin S, El-Hamamsy I, Frischmeyer-Guerrerio PA, Guerrerio AL, et al. Loeys-Dietz syndrome: a primer for diagnosis and management. Genet Med. 2014;16:576-87.

21. Loeys BL, Schwarze U, Holm T, Callewaert BL, Thomas GH, Pannu H, et al. Aneurysm syndromes caused by mutations in the TGF- $\beta$ receptor. $N$ Engl J Med. 2006;355:788-98.

22. Loeys BL, Chen J, Neptune ER, Judge DP, Podowski M, Holm T, et al. A syndrome of altered cardiovascular, craniofacial, neurocognitive and skeletal development caused by mutations in TGFBR1 or TGFBR2. Nat Genet. 2005;37:275-81.

23. Price J, Magruder JT, Young A, Grimm JC, Patel ND, Alejo D, et al. Long-term outcomes of aortic root operations for Marfan syndrome: a comparison of Bentall versus aortic valve-sparing procedures. J Thorac Cardiovasc Surg. 2016;151:330-8.

24. Patel ND, Weiss ES, Alejo DE, Nwakanma LU, Williams JA, Dietz HC, et al. Aortic root operations for Marfan syndrome: a comparison of the Bentall and valve-sparing procedures. Ann Thorac Surg. 2008;85:2003-11.

Key Words: Loeys-Dietz syndrome, Marfan syndrome, pediatrics, valve-sparing aortic root replacement

\section{Discussion}

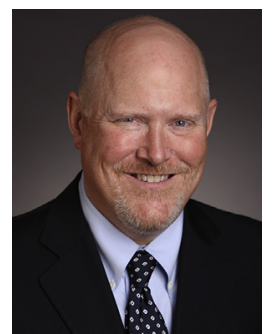

Dr J. Tweddell (Cincinnati, Ohio). That was a great series and presentation, Luca.

Dr Vricella and colleagues have summarized the largest experience with valve-sparing aortic root reconstruction in children, a series that goes back 20 years and includes 100 patients, which would make the statistical analysis more straightforward. The primary technique that they used is reimplantation using the sinus of Valsalva graft. I would just have to say that this technique developed by Drs Cameron and Vricella is well established, elegant, and reproducible and is the technique that I have used in approximately 30 young patients.

How do you select the appropriate graft size for the patient? In the article you discussed using the sinotubular junction, whereas typically I would use the aortic annulus to size, the predictive size of the graft.

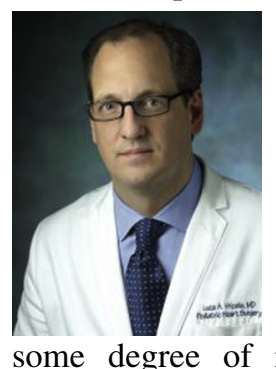

Dr Vricella (Baltimore, $M d$ ). There are a variety of formulae for that. I think it's more an art than a science. The majority of these patients, especially patients with connective tissue disorders and large aortic root aneurysms, will have a competent aortic valve. There was a minority of patients who had some degree of regurgitation; it was usually central. 
When the valve is competent or just mildly regurgitant, we will size to the sinotubular junction, and if the annulus is larger, we will create some vertical slits to accommodate the graft around a larger annulus.

Also as I have seen in this particular patient series, the annulus is usually not that large, and if it is really large, we would then place some plication sutures or reduce the size of the annulus, although if you are taking full-thickness bites, you can predispose the patient to develop a pseudoaneurysm later. So in the majority of patients, we actually size to the sinotubular junction. If the valve is regurgitant, it's a bit more of an art. In these cases, once the valve is resuspended, then we will adjust the valve with free margin plication, for example.

Dr Tweddell. Have you used this technique for patients with acute dissection? I have a couple of patients who presented with acute root dissection and used this strategy.

Dr Vricella. The best strategy in aortic dissection is to get the patient off the table. I think it depends on what kind of dissection there is. Clearly not in this particular series, but I have used a valve-sparing procedure in a patient with dissection, but it was a proximal dissection without tremendous hemodynamic compromise or malperfusion. In these cases, I would be more conservative rather than aggressive. If you try to preserve the valve and the valve is regurgitant, you have to reclamp a patient who is ready for a composite root replacement or replace the valve within the graft. In the Hopkins experience, that is now more than 350 cases, there are probably less than 5 patients with aortic dissection who underwent a valve-sparing operation.

Dr Tweddell. You discussed the age range of the patients. In these children who require a valve-sparing root reconstruction, the aortic root is large, and you can almost always, as you pointed out, accommodate an adult-sized prosthesis. You had 1 patient in your series who was 9 months of age. What do you do with a patient whose aortic annulus is perhaps $18 \mathrm{~mm}$ or less? Have you encountered those patients and what strategy do you use in those patients?

Dr Vricella. The majority of patients in our series had connective tissue disorders, and a minority had congenital heart disease. Most children with connective tissue disorder will have a large annulus to start with. In some of the really small ones, we use a Tirone David 1 procedure where you just reimplant the valve within a straight tube graft or a smaller diameter Valsalva graft; there is probably a role for a Yacoub-type of operation in these kids without encasing the root all the way down below the nadir of the sinuses, anticipating at some point the leaflets may splay out and you may need to intervene. We have used the remodeling technique in smaller children and patients with congenital heart disease in whom extensive dissection was difficult, such as in patients with conotruncal abnormalities.

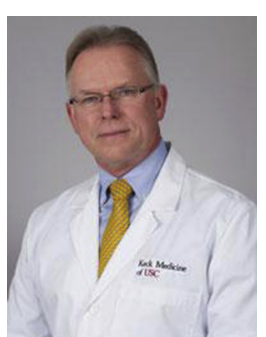

Dr V. Starnes (Los Angeles, Calif). Luca, a great presentation. I think one of the important parts of this article is the durability of the leaflets. The fact that you have used this operation in a lot of patients with collagen vascular diseases and those leaflets held up over that period of time gives us all a lot more encouragement to use this technique in patients with Marfan and LDS.

What do you do with the buttons and button size, particularly in those with LDS? Do you do something to reinforce the backing of them, because I have seen some button aneurysms coming back.

Dr Vricella. I showed the 1 patient in whom we reintervened, and we thought that these were true aneurysms of the button. Instead, what happened is that the suture line simply melted away. What we try to do is keep the button as small as possible. Sometimes you see a small ridge at the bottom of the button. The suture line needs to be closer to the inferior ostium of the coronary because that ridge can protrude into the lumen and obstruct flow. Usually, we will reimplant the small button and reinforce the suture line circumferentially with a Teflon felt strip and then reinforce it with a sealant.

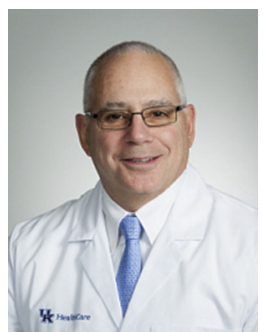

Dr J. Quintessenza (Lexington, Ky). A great job and great work, and I noticed over many years just an excellent endeavor you have all taken. My question has to do with the valve repair cases and how did that correlate with durability? I think we are learning more about, as we all do, geometry of the aortic root, what happens with the leaflets, and the evaluation either intraoperatively or postoperatively with advanced imaging might lend additional help to improve durability.

Dr Vricella. So, what do we do with the aortic valves? In terms of repair, we have used rather simple techniques and have a relatively low threshold for replacing the valve. If you have to do a lot more than just restoring the symmetry of the valve with free margin plication or if a valve is bicuspid, calcific, or more than mildly stenotic, we will probably replace that valve. But we have been very encouraged. None of the patients who were repaired in this particular series needed to go back for replacement later on.

Dr Quintessenza. So are the patients receiving repair not in the failure mode essentially?

Dr Vricella. No. As long as you have coaptation height and have to resuspend the leaflets high into the graft, the stability of valve repair is maintained over time. 


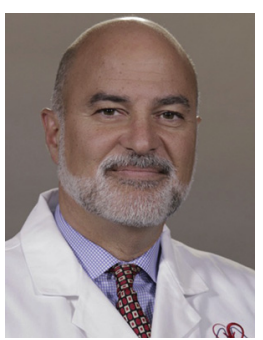

Dr E. Bacha (New York, NY). Luca, a great talk, and you and Duke are recognized masters at this operation. My question is on the LDS cases, specifically the teenage patients, how do you decide to go more distal into the arch and do you do hemiarches? You had a few type B dissections in your series.

Dr Vricella. We are relatively conservative, although the fact that we have to reintervene at some point in the future in some of these patients leads us to think if we should be more aggressive with the arch. Most of these patients when they present with aortic root aneurysm will actually have a normal aortic arch. It is kind of hard to just extend the replacement to the aortic arch if overall only $20 \%$ of patients with Marfan syndrome or LDS are going to return for an arch replacement. We have replaced the arch after root replacement in this patient group with low morbidity and mortality.

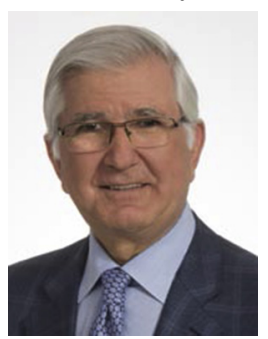

Dr T. David (Toronto, Ontario, Can$a d a$ ). You presented 3 false subaortic aneurysms beneath the reimplantation, and your recent article in the Journal described 4 false aneurysms beneath the aortic valve. The question is to you and Duke. This, I believe, is really your modification of the original operation.

In patients with connective tissue disorder, particularly with LDS where the tissues are miserable to stitch anything, 3 stitches to hold the graft in the outflow tract are inadequate. The question is, were the false aneurysms related to the technique, to these 3 stitches that Duke used for reimplantation?

Dr Vricella. I agree. In the cases that we have seen where we had to go back and do a patch exclusion of the area, it is typically where the stitch was placed. All the patients with pseudoaneurysms are patients with LDS. We haven't seen this in patients with Marfan syndrome. So what I have done personally is in that area, once the graft is seated and the lower 3 sutures are in place, I will put 2 additional sutures.

Dr David. If you read how I came to this operation, we usually use a band to reduce the aortoventricular junction in patients with bicuspid aortic valve and a very large annulus, and then we evolved to the reimplantation. But from the beginning, we thought that it is important with at least 9 or 12 stitches in the bottom to hold those particular areas together. I think the aortoventricular junction is the key in this operation. Of course, in a very small child it would be impossible to put any more than the number that the size allowed.

Dr Vricella. Well, we went from 9 to 3, and maybe now we are starting to go back to more sutures. But we just reinforce that area to avoid that and disperse the tension on the proximal aortoventricular junction.

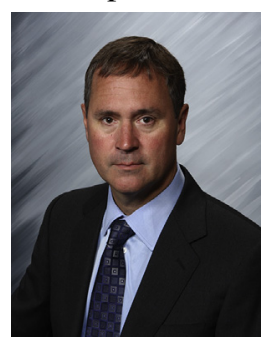

Dr Moon. Dr Cameron, do you have some comments, because this is a large portion of your patients.

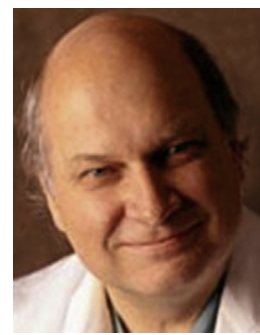

Dr D. Cameron (Baltimore, Md). I want to emphasize what Luca said, that the subannular pseudoaneurysms have really been in the LDS cases, not the Marfan, and, as I recall, I know at least 1 of them occurred in a patient who had multiple subannular sutures. So it can occur even with a lot of sutures.

Whether or not there might be some subgroup of very aggressive LDS cases who do need more than 3, I think that is a valid question. We have occasionally added a few sutures in the noncoronary sinus or below the noncoronary sinus. That's where most of them occur. There's something about the aortomitral apron in LDS that I think makes it particularly vulnerable to the sutures tearing a bit.

Dr Moon. Dr Tweddell?

Dr Tweddell. My last question is concerning the indications. The majority of valve-sparing root reconstructions are done prophylactically to prevent the complications of aortic root dissection. The indications we currently work on are based on the presence of a genetic syndrome, the absolute size, the recent enlargement, the family history, which is probably only important in patients with Marfan, and the patient's absolute age. It seems like that the indications for the most extreme phenotype of LDS is the fact that they haven't had an operation yet.

But I wonder if we are calibrating this properly. This is a big operation; it's a prophylactic operation with identifiable mortality and long-term morbidity. Do you think we have the right criteria, and could you speculate on the potential for future criteria? Are there biomarkers we should be looking at in the future to help us guide when we should approach these patients?

Dr Vricella. Yes, you are right, it's kind of a moving target. For the younger patients, right now we are looking more at some phenotypes, like your arterial tortuosity index, for example, or a craniofacial score, for example; the worse these are, typically in the more infantile forms of LDS, the higher the propensity for a vascular catastrophe. So for those children, we will actually go down to a lower diameter, $31 / 2 \mathrm{~cm}$. And when you go in, as you know, and you dissect the root out, it's very thin. So most of the time when I am in there even at $31 / 2$ or $4 \mathrm{~cm}$, I think we are there for the right reason. 